\section{Updated results of the thalassaemia prevention programme carried out in Latium}

Previous results of our programme have been published in this Journal. ${ }^{1-3}$ Its basic concept is that both the distribution of information about the prevention of Mediterranean anaemia (thalassaemia) and the mass screening for thalassaemia carriers must be carried out much earlier than adulthood and must not be exclusively aimed at pregnant women or already established couples. Early timing of the preventive actions now available provides thalassaemia carriers with a number of options for prevention (including the choice of a non-thalassaemia carrier partner) besides making the option of selective abortion earlier, easier, and more widely adopted.

Based on these grounds, the preventive programme carried out in Latium from 1975 by the Centro di Studi della Microcitemia di Roma, supported by Regional Health Authorities of Latium, consists of the following.

(1) Distribution of information throughout the population of reproductive age, starting with teenagers who can be most conveniently contacted at secondary schools. After this first stage, the most practical and successful methods have proved to be: meetings of the Family Health Services; delivery of pamphlets and other explanatory material to people shortly to be married in the General Registry Office; periodic requests to all Public Health Officers in order to make them secondary sources of the relevant information; and the repeated use of the mass media.

(2) Mass screening of two types: annual screening of final year students in secondary schools, and continuous screening of school leavers, who come on their own initiative to be examined at the Centre. The number of

TABLE 1 Results of the Latium thalassaemia prevention programme (October 1975 to June 1988).

\begin{tabular}{lr}
\hline Population screening & \\
Secondary school students & 606661 \\
Young adults & 68093 \\
Total & 674754 \\
Non- $\alpha$ thalassaemia carriers & \\
Secondary school students & 11502 \\
Young adults & 15116 \\
Total & 26618 \\
Identified couples at risk & 275 \\
Pregnancies at risk investigated & 126 \\
Homozygous fetuses aborted & 36 \\
\hline
\end{tabular}

Journal of Medical Genetics 1989, 26, 667

TABLE 2 Fall in incidence of thalassaemia in Latium from 1975 to 1986.

\begin{tabular}{lcc}
\hline Years & \multicolumn{2}{l}{$\begin{array}{l}\text { Incidence of new affected } \\
\text { children/100 000 live births }\end{array}$} \\
\cline { 2 - 3 } & No* & $\%$ \\
\hline $1975-1976$ & $23 / 143156$ & $16 \cdot 04$ \\
$1977-1978$ & $24 / 128221$ & $18 \cdot 71$ \\
$1979-1980$ & $12 / 116835$ & $10 \cdot 27$ \\
$1981-1982$ & $14 / 110332$ & $12 \cdot 69$ \\
$1983-1984$ & $8 / 106087$ & $7 \cdot 54$ \\
$1985-1986$ & $3 / 99967$ & $3 \cdot 00$ \\
\hline
\end{tabular}

*Statistical data of the Italian Central Institute of Statistics, 1986.

these has increased from an initial 100 per month in 1975 to the present 1800 .

(3) Genetic counselling for all single and married thalassaemia carriers. There are about 44000 such carriers of reproductive age in this region $(0.022 \times 2000000)$ and approximately 500 couples at risk.

Up to June 1988 about $60 \%$ of the non- $\alpha$ thalassaemia carriers and $55 \%$ of the at risk couples of reproductive age in Latium have been identified (table 1) and 36 homozygous fetuses have been aborted. Overall the reduction in the incidence of Mediterranean anaemia achieved in the 1985 to 1986 period by comparison with 1975 to 1976 was $81 \%$ (table 2).

\section{Bianco, B Graziani, M Lerone, D Ponzini, M C Aliquo', and E Foglietta Associazione Nazionale per la lotta contro le Microcitemie in Italia, Centro di Studi della Microcitemia di Roma,} Rome, Italy.

\section{References}

1 Silvestroni E, Bianco I, Graziani B, Carboni C, D'Arca SU. First premarital screening of thalassaemia carriers in intermediate schools in Latium. $J$ Med Genet 1978;15:202-7.

2 Silvestroni E, Bianco I, Graziani B, et al. Screening of thalassaemia carriers in intermediate schools in Latium: results of four years' work. J Med Genet 1980;17:161-4.

3 Bianco I, Graziani B, Lerone M, et al. A screening programme for the prospective prevention of Mediterranean anaemia in Latium: results of seven years' work. J Med Genet 1984;21: 268-71.

Correspondence to Dr I Bianco, Centro Studi della Microcitemia di Roma, Via Treviso 29, 00161 Roma, Italy. 